\title{
Strategic Communication and Prevention of Violent Extremism through Education: The Case of Kosovo
}

\author{
Mimoza Hasani Pllana \\ Postdoc (cand.), University of Sofia, \\ "St. Kliment Ohridski", Bulgaria
}

DOI: https://doi.org/10.36941/jesr-2021-0034

\begin{abstract}
Strategic communication is an important asset when countering violent extremism at an institutional level, whereas its objective is to give emphasis to internal communication models that function within given organizations and institutions. Internet is one of the main communication frameworks used by violent extremist groups nowadays. Social media networks, such as YouTube for example, are among the most used communication forms used to recruit youngsters and other persons to join the conflict zones in the Middle East. State institutions in Kosovo have acted in preventing violent extremism by drafting national level strategies countering violent extremism. One of the main pillars that is foreseen as an important tool to prevent and react against this negative phenomenon is better education of children and youngsters. Therefore, national education institutions have an important responsibility to counter extremist narratives through internal and external communication as well as to address issues that can aggravate violent behavior and actions.
\end{abstract}

Keywords: strategic communication, countering violent extremism, state reaction, education

\section{Introduction}

Drafting of strategic documents, including the strategic communication document for the prevention of violent extremism in Kosovo has come as a need for a necessary response, especially after the publication of international and local reports in 2015 when the number of Kosovar citizens who joined the fighting in the Middle East has exceeded number of 200. This year, as an emergency response step, the state approves the Strategy on Prevention of Violent Extremism and Radicalisation Leading to Terrorism 2015-2020, which defines a series of actions in three steps: prevention, response and reintegration. To the first step - prevention, in addition to other activities, special importance was given to inter-institutional communication, to prevent the spread of narratives that promote extremist ideology, strengthening internal and external communication at the country level. Following this action, the state reacts by supporting new initiatives that specifically deal only with actions related to strategic communication to prevent violent extremism, against this negative phenomenon and reintegrating into society cases returned from crisis in the Middle East.

At this point, education is seen as one of the strong pillars of state strategy and initiatives against the spread of narratives and extremist actions in the country. How does it happen? Through curricular 
and extracurricular programs, such as: programs for the development of critical thinking among young people as a means for implementation of reforms in education and as a golden opportunity to prevent young people from falling prey to the interests of extremist groups; safe internet programs, which aim to raise awareness of young people about the Internet threats, especially communication with strangers; then, programs for early identification of risk factors, raising awareness of the family community through the advice of parents in schools and the community of teachers, through continuous communication with children/students, in order to prevent the use of extremist behaviors and actions that lead to radicalization and terrorism.

Through education, activities are defined that help in referring cases of violence, such as: didactic manuals for the inclusion of the component for risks arising from extremism in the pre-university education curricula and then the implementation of this curriculum at all levels of pre-university education, further, inclusion of topics for the prevention of extremism in programs on gender issues through education on topics such as prevention of domestic violence, prevention of trafficking in human beings, promotion of gender equality in schools, etc.

The reaction as a measure of inter-institutional communication empowerment is seen in the implementation of the regulation on prevention and referral of violence in pre-university education institutions (Kosovo Government, 2013), which defines communication at the vertical and horizontal level of all state public institutions, and finally strengthens mechanisms for the reintegration into regular education of children and young people returning to Kosovo from the conflict zones in Syria (Kosovo Government, 2015). In face-to-face interviews in Radio Free Europe, young Kosovars who have returned from Syria confess that their union with extremist groups in Syria was prompted from social media and YouTube (Radio Free Europe, 25 October 2016).

\section{Methodology}

Qualitative method was conducted in this research, including the epistemological and ontological approach. Using the qualitative method, we have made efforts to analyze the documents of the state related to the fight against extremism, which have been approved by the Government and published on the official websites. We have also analyzed reports of centers and local and international organizations that through their programs fight violent extremism and the spread the extremist ideologies by certain extremist groups, as well as research related to narrative and counter-narratives. From an epistemological and ontological point of view, we have tried to understand what forms and methods of communications the certain groups have used to increase trust and change people's belief to join extremist groups. To analyze the experience of people involved in the crisis in the Middle East, in order to identify the narratives used by extremist groups, we used interviews that researchers and journalists conducted with resonators involved over the phone calls or face-to-face contacts.

\section{Synchronization of Messages and Institutional Actions in the Field of Education Against Violent Extremism}

A simple communication process always involves sending a message from sender to recipient. Strategic communication has another purpose function that necessarily requires planning, synchronization and monitoring of message transfer from sender to recipient. We are talking here about a process that requires synchronization of messages and actions. Strategic communication is a new concept that has found use in recent years in several areas, so there are many explanations for the concept "strategic communication".

In this article we see the function of strategic communication from a perspective that includes education and that relates to national security. We will analyse why strategic communication has become necessary to combat violent extremism, specifically the role of education in this strategic process. We took the case of Kosovo as one of the countries with the highest participation of its citizens in the Syrian conflict to see how the institutions respond against this urgent need for prevention, 
response and reintegration; why institutions had to communicate differently in this case; how internal and external communications have developed that persuaded the Government to come up with the initiative to draft a communication strategy against violent extremism. We will also see what was the previous approach of Kosovo institutions to maintain peace and security in a newly established state that makes efforts to fight against the spread of this negative phenomenon. In particular, we will analyze the internal communication and external communication of educational institutions in order to prevent, respond and reintegrate, as three steps that are the essential elements of the Strategy for the Prevention of Violent Extremism and Radicalization Leading to Terrorism 2015-2020.

\section{The Chronology of the Drafting Process of the Strategy Against Extremism}

In 2015, local and international reports, Kosovar and foreign media reported that Kosovo was listed among the countries with the largest number of foreign fighters involved in the Syrian conflict. According to reports, the fighters were not alone, with them were also women and children, whom they had taken with, following their dislocation alone. But the media also counted cases when spouses went to Syria together. Recently (January 2020), AP News Agency brought the story of a man and a woman from Kosovo who in 2015 left their country to become part of the fighting in Syria. "Kosovo woman, man repatriated from Syria charged with terror", begins the story, as Kosovo prosecutors filed terrorism charges against an Albanian woman and a man for allegedly joining the Islamic State ranks in Syria. V.K. and the man identified as F.D. left Kosovo in March 2015 first go to neighboring Skopje, North Macedonia, and then to Turkey where they crossed to Syria. We quoted this report to go back to 2015 when the Government of Kosovo was alerted by the media about the large number of Kosovars going to Syria, and how the number continued to grow. Government failed to react swiftly and take concrete steps to prevent citizens from going to the areas where fighting was taking place, except for a few arrests of persons suspected of being involved in terrorist actions or terrorist organizations.

In the same year, the Kosovar Center for Security Studies in Pristina, published the report that investigates the causes and consequences of the involvement of Kosovar citizens as foreign fighters in Syria and Iraq. The report revealed a shocking fact that in the first half of 2015, compared to per capita (per million inhabitants) in terms of the number of foreign fighters, Kosovo was ranked first among the 22 countries listed, followed by Bosnia, Belgium and Albania. According to the report, most of the fighters joined the Syrian conflict during 2013 (Kursani; 2015).

In that year, the conflict in Syria awakened Kosovo institutions to react and as an immediate measure the Government of Kosovo drafted and approved the Strategy for the Prevention of Violent Extremism and Radicalization Leading to Terrorism 2015-2020. The strategy was divided into 4 objectives:

1. Early identification of causes, factors and target groups,

2. Prevention of Extremism and Violent Radicalism,

3. Intervention in order to prevent and reduce the risk from violent extremism and

4. Deradicalization and Reintegration of radicalized persons.

Strategic objectives also included 23 specific objectives and about 100 activities in the National Action Plan. With the approval of the Strategy, the National Coordinator Against Extremism was appointed in order to fully implement and monitor the Strategy and Action Plan. This approach was partially successful. During the years 2015 to 2020, a series of researches and reports were conducted regarding the implementation of the Action Plan and the achievement of strategic objectives set by the Government of Kosovo.

Despite the great efforts of Kosovar institutions to create a calm and safe environment for its citizens, they did not feel quite safe even three years after the adoption of the Strategy. According to the Kosovo Security Barometer, published in 2018, about $75 \%$ of Kosovar citizens surveyed considered violent extremism a threat to society. These data were further stratified by asking for specifics such as from where the fear came from and according to the same barometer, the response of the majority of citizens surveyed was that the greatest threat came from violent extremism based on religion (Gashi, 
2018, p. 6-7).

Further, due to the difficult circumstances created as a result of the COVID 19 virus pandemic, in 2020 an evaluation report was not conducted by the National Coordinator Against Extremism and Terrorism, but as a reference point for further developments in this field was used the report on the Evaluation of the Strategy for the Prevention of Violent Extremism and Radicalization Leading to Terrorism 2015-2020, published in January 2020 and drafted during 2019 by the Office of of the National Coordinator Against Extremism and the United Nations Migration Organization-IOM.

In this report the main results were that the strategy has responded to the needs of the time in 2015 by creating an inter-institutional synergy in order to manage the situation and deal with the phenomenon, and that the strategy has addressed many issues of interest to deal with the phenomenon. The strategy also has unified institutional efforts to address the issue by raising awareness at the level of institutions but also of society in order to recognize the threat coming from extremism (IOM \& Kosovo Government, 2019, p.8-9).

Furthermore, the report publishes a major challenge, which is internal and external communication, assessing that there has been no structured inter-institutional approach, and that the local level is not sufficiently involved in the process of drafting and implementing the Strategy and as a result local governance structures do not have enough information on the issues and their role in this process (IOM \& Kosovo Government, p.3-4).

Involvement of the local / municipal level in the prevention of violent extremism is also recommended by the publication "Community Perspectives on Violent Extremism Strengthening local factors of social resilience", by assessing that the municipality (or local administration) should take the lead in establishing 'community relations committees' to offer space for regular discussions involving different community groups. This would bring together different stakeholders (women, youth, representatives of ethnic groups, religious groups, etc.) in order to detect early signs of radicalisation or recruitment into violent extremist groups and allow scope for early action (Morina, Austin, Roetman \& Doudet, 2019).

Regarding the development of inter-institutional communication in horizontal and vertical lines, although the central group that drafted the Strategy has followed the approach and instructions of the Government of Kosovo, and that the Strategy was developed through a consultative process between institutions, civil society and development and strategic partners, effective communication with local authorities has not been achieved, which has left the municipal level out of function for the implementation of activities and achievement of strategic objectives.

This assessment highlights the lack of internal communication starting from the time of drafting the strategic document. So, strategic communication turns out to have been the biggest challenge that has hindered the implementation of the activities set out in the Action Plan starting in 2015 and until 2020 .

In conclusion, one of the strong recommendations is to improve inter-institutional communication and coordination, such as drafting a Communication Strategy and counter-narratives to extreme ideologies in order to prevent the spread of extremism.

\section{Inter-Institutional Communication}

Inter-institutional communication assisted the Government of Kosovo in its efforts to fulfill its strategic mission to achieve certain objectives through cooperation with development partners, civil society and the media, but it was not sufficient to synchronize messages and actions in certain situations.

Thus, inter-institutional communication was only an insufficient "tool", but important in view of the implementation of the Strategy for the Prevention of Violent Extremism and Radicalization in Terrorism 2015-2020. Institutions obliged to carry out the activities set out in the Action Plan, established communication in three areas: prevention, response and reintegration through work in two groups coordinated at the governmental level, the political group and the technical group.

Inter-institutional communication used to prevent extremism includes the largest number of 
activities for the prevention of all negative phenomena leading to extremist behavior. In line with each other, the leading institutions for the development of sustainable policies against violent extremism are: Ministry of Education, Science and Technology (MEST), Ministry of Internal Affairs (MIA), including the Kosovo Police (KP) and Kosovo Intelligence Agency.

In this structure, the role of educational institutions is on an equal footing with the role of security institutions, given the fact that young people were the main target of recruitment and mobilization efforts by violent extremist organizations. Psychologists attribute this sensitivity to several factors, including, but not limited to, the search for identity by young people, finding meaning in life, society, purpose, cognition, and belonging. Naturally explosive nature and willingness to take greater risks can be contributing factors to young people's tendency to join groups or movements that support violence (OSCE, 2018).

\section{Prevention}

Following we will analyze the results in the field of education as a product of inter-institutional communication for the prevention of violent extremism, response to violent extremism and reintegration of children returned from conflict areas in Syria in the educational process according to regulations and the Law on Pre-University Education.

- Ministry of Education, Science and Technology:

- Communicates with educational institutions to draft policies for the prevention of negative phenomena in schools;

- Communicates with municipal directorates of education and schools in order to resolve conflicts between peers;

- Accredits training programs for teachers in order to strengthen the competencies to distinguish violent behaviors of children during the learning process

- Manages and reflects cases of violence in schools through the online Education Information Management System;

- Develops programs that promote children / human rights / values of tolerance, equal opportunities, the development of critical thinking, useful use of the Internet, law enforcement, etc.

\section{Reaction}

The response includes the second important step of inter-institutional communication in the function of intervention to prevent and reduce the risk of violent radicalism.

- Mechanism

Implements regulation QRK-NR 21 / 2-13 on the protocol for prevention and referral of violence in pre-university education institutions and negative phenomena. The implementation of the regulation obliges a number of institutions to communicate with each other.

\section{Reintegration}

Reintegration includes the third step of the Strategy and aims to provide assistance to radicalized individuals to move away from radical / extremist ideology and to renounce violence.

- Mechanism

In this regard, proper inter-institutional communication is required for the provision of a range of social, health (physical and psychological), educational (formal and non-formal education) services, professional development, support from society, then preparation of professional staff for the implementation of resocialization policies and programs as well as 
identifying the needs for the creation of new programs which result in the full reintegration of returnees in Kosovo society. MEST conducts inter-institutional communication for reintegration in regular education based on the legislation in force.

\section{Strategic Communication}

We mentioned that there are ongoing dilemmas about the definition of the concept of strategic communication. Researchers and analysts in the field, consider the dilemmas about the differences between strategic communication and ordinary inter-institutional communication and communication with the public as common when addressed by ministries, public institutions, organizations, etc., which in trying to develop strategic communication, create confusion.

A similar situation has occurred with Kosovo during the years of implementation of the Strategy Against Violent Extremism and Radicalism Leading to Terrorism (2015-2020).

The concept of strategic communication is new in the field of communication, so communication researchers provide different explanations. The researcher of social communication and strategic communication, Cristian E. Guerrero-Castro, gives some interesting explanations regarding the muchdiscussed concept of strategic communication.

One of Guerrero-Castro's explanations that aligns with the goal of Kosovo institutions on the need to draft a Communication Strategy Against Violent Extremism, refers to the synchronization of words and actions as they are perceived by selected audiences; programs and activities deliberately aimed at communicating and engaging with intended audiences, including those implemented by public affairs, public diplomacy and information operations professionals (Guerrero-Castro, 2013).

Thus, Kosovo institutions in pursuing efforts to implement the National Strategy and Action Plan Against Violent Extremism have faced challenges that include internal communication and external communication. Non-synchronization of activities and messages was evident in the three phases of the strategic document prevention, response and reintegration. Following we will present two situations that create confusion as a result of lack of coordination of internal communication and communication with the public:

1. In the framework of the third strategic objective, the intervention, as the first activity is the implementation of the regulation QRK-NR 21 / 2-13 on the protocol for prevention and referral of violence in pre-university education institutions, as a strategic framework in orienting institutional action to address evidence-based violence.

The protocol examines possible types of violence that occur in educational institutions at the preuniversity level, offers practical proposals on what teachers can do to prevent any form of violence, explains ways to identify violence and procedures for inter-institutional communication for intervention and referral. cases of violence in relevant institutions. The key institutions for the implementation of the protocol are educational institutions from the Ministry of Education, Science and Technology up to the school level, then institutions for labor and social welfare from the Ministry of Labor and Social Welfare up to the centers for social work; security institutions headed by Kosovo Police and finally the Ministry of Health up to family medicine centers. Thus, communication and coordination of actions is necessary by all institutions mentioned in order to carry out institutional activities and obligations to identify and respond to all types of violence in pre-university education institutions. As a flaw, the Ministry of Health and other health institutions are not included in the Action Plan against Violent Extremism. In this form, during five years of the existence of the strategy, one of the most important links in the inter-institutional chain has been detached and as a result the protocol has found minimal applicability.

2. The lack of strategic communication and conflicting messages in the public becomes apparent even during the implementation of the activities defined in the strategic objective, Deradicalization and Reintegration, specifically during the implementation of the activity for reintegration of children (returned from conflict areas) in regular education according to the legislation in force. 
The following are the contradictory messages that were sent to the public on September 2, 2019, the day when classes were starting for all children living in the Republic of Kosovo and for 29 children returning from Syria ( 5 in preschool and 24 in pre-university education). On this occasion, the than Minister of Education, Science and Technology, Mr. Shyqiri Bytyqi, informed media that children returned from Syria are not yet ready to start school, emphasizing that MEST is making final preparations and once everything is ready children will be integrated into regular classes. On the very same day, Minister of Justice, Mr. Abelard Tahiri, shared to media and public opinion his great satisfaction that the children returned from Syria to Kosovo, started school at the level of primary and lower secondary education. These two contradictory public statements created confusion among all government institutions, diplomatic missions in Kosovo, development partners, civil society and monitors of the process of reintegration of children returned from Syria into social and educational life. After multiple reactions, hours later MEST explained to the public through its website that on September 2, school-age children returned from the hearths of war have started school and that the education process has also started for students whose age is older than the age provided by the Law on Pre-University Education to be regular students. This opportunity for integration in the education process has been provided by MEST in cooperation with the Municipal Directorates of Education in all municipalities of the Republic of Kosovo. In this case MEST has not complied with basic principles of a public press statement that must include reliable information modeled and filtered through a complex process before it reaches out to the public (Hasani-Pllana, 2020, p.141).

These and similar situations come as a result of the failure of Kosovo's institutions to use the opportunities available to them for strategic and sustainable communication to address violent extremism.

During the implementation of the first strategic document, despite the great results achieved by the security institutions in the field of intervention, there was a lack of consistency and coordination between institutions in the prevention and reintegration phases. Therefore, with the drafting of the new strategic document, it is deemed necessary to increase inter-institutional coordination, create new opportunities and use the existing classic opportunities for communication with the public.

Following the publication of the evaluation reports, we see that the non-harmonization of internal and external actions and messages has not been researched yet, however, in the general reports it is estimated that strategic communication was one of the challenges that accompanied the implementation of this document. from approval to completion. As a result, the Government of the Republic of Kosovo, from 2018 onwards in cooperation with various development partners is making efforts to draft a Strategy and Action Plan that would regulate planning and actions, would unify messages and media relations through a spokesperson in close cooperation with the National Coordinator Against Extremism. The Government of Kosovo aim is to position the Communications Strategy Against Violent Extremism at the center of every action.

What to do when writing a scientific discussion

Summarize your results and describe their interpretation in light of the familiar literature. ...

Explain the Importance of Your Results. ...

Acknowledge the shortcomings of the study....

Discuss Any Guidance for the Future. ...

Do not repeat your results.

\section{Conclusion}

Strategic communication is considered an important action for the state and extremist groups. Strategic communication for prevention the violent extremism through education for the state aimed drafting counter narrative of extremist narratives and aimed to strengthen communication between institutions to raise awareness of people about the dangers that can come from violent extremism. In our case study, communication with young people through education was purposeful and with a special function, preventing the spread of extremist ideology to young age groups, through education. These 
actions have shown success in early identification of children who have expressed violent and extremist behavior which has prevented the development of their further orientation. Communication between educational institutions has promote the mobilization of school staff, teachers and leaders to exercise their role and within this perspective. Communicating with parent councils within the school has strengthened the role of the family in preventing extremism and referring cases that may be involved in the activity of this field. Strategic communication is also considered an important action for extremist groups, as well. Based on the stories of returnees from the conflict zone in Syria, we understand that communication through social media and YouTube was one of the strategic forms of communication for recruiting young people to become part of the armed conflict in the Middle East. In this case, we estimate that the state, in addition to working in institutions, should see the possibility of fighting extremist narratives also through social networks and you tube.

\section{Discussion}

In order to achieve a professional and successful communication, from 2015 onwards, working groups at the level of government, administrative levels and development partners, including civil society, have been established in Kosovo, as well as action plans and strategies against extremism have been drafted, making attempts for a genuine communication in the horizontal and vertical line. During this time, results have been achieved in preventing violent extremism, identifying push and pull factors; structuring institutional actions and increasing the capacity of educational staff, social workers, psychologists, psychiatrists and other officials who during their work face this negative phenomenon. Then, further results have been achieved in raising public awareness of the dangers posed by the violent extremism that Kosovo has faced in recent years. However, various reports indicate that in the period 2015-2019, despite the achieved results, there was a lack of proper inter-institutional communication. Therefore, Kosovo has responded to the need by initiating a series of activities to build the capacity of of teachers, psychologists and has taken steps towards drafting a Communication Strategy Against Extremism that helps increase institutional inclusion, civil society, media and development partners in function of preventing violent extremism in the country.

\section{References}

APNews. (14 Janurary, 2020). Kosovo woman, man repatriated from Syria charged with terror, the link: https://apnews.com/article/e7f7c204b6e71b3530862186cbo97495

Guerrero-Castro, C. E. (2013). Strategic Communication for Security \& National Defense: Proposal for an Interdisciplinary Approach. Connections: The Quarterly Journal. 12(2)

Gashi, A. (2018), Civil Society Preventing and Counterning Violent Extremism in Kosovo, Partners Kosova Center for Conflict Managment, Prishtina

Hasani Pllana, M. (2020). Linguistic Forms and Text Functions. Academic Journal of Interdisciplinary Studies, 9(3), 141. https://doi.org/10.36941/ajis-2020-0049

Kursani, Sh. (Aprill 2015), Kosovar Center for Security Studies, Report inquiring into the causes and consequences of Kosovo citizens' involvement as foreign fighters in Syria and Iraq, http://www.qkss.org/en/OccasionalPapers/Report-inquiring-into-the-causes-and-consequences-of-Kosovo-citizens-involvement-as-foreignfighters-in-Syria-and-Iraq-408

Morina, E., Austin, B., Roetman T.J., \& Dudouet, V., (September 2019), Community Perspectives on Violent Extremism Strengthening local factors of social resilience, berghof-foundation, https://www.berghoffoundation.org/fileadmin/redaktion/Publications/Policy_Briefs/PolicyBriefo9_PVE_ËesternBalkans.pdf

Ministry of Education, Science and Technology, Ministry of Education Science and Technology (MEST) Explains that, today, school-age children returned from the hearths of war have also started learning, (o2 September), https://masht.rks-gov.net/article/sqarim-13

Office of the National Coordinator Against Violent Extremism and Terrorism, International Organization for Migration (2020), Evaluation of the strategy for the prevention of violent extremism and radicalism leading to terrorism $(2015-2020)$. 
Organization for Security and Co-operation in Europe, (August 2018), The Role of Civil Society in Preventing and Countering Violent Extremism and Radicalization that Lead to Terrorism-A Guidebook for South-Eastern Europe, Vienna, https://www.osce.org/files/f/documents/2/2/400241_1.pdf

Kosovo Government, (2015), Strategy on prevention of violent extremism and radicalisation leading to terrorism 2015-2020, http://www.qkss.org/en/Capacity-Development/Strategy-on-prevention-of-violent-extremismand-radicalization-leading-to-terrorism-2015-2020-653

Kosovo Government, (20013) Regulation QRK - no.21 for protocol for the prevention and reference of violence in institutions of pre-university education2,http://www.kryeministri-ks.net/repository/docs/rregullore_qrknr_21_2013_per_protokollin_per_parandalimin_dhe_referim....pdf)

Radio Free Europe, (o2 September 2020), Contradictory notices for children returned from Syria to Kosovo, https:/www.evropaelire.org/a/30142466.html,

Radio Free Europe, (o2 September 2020), Tahiri: We have rescued 74 Albanian children from the horrors of the war in Syria, https://www.evropaelire.org/a/30142363.html

Radio Free Europe (25 October 2016), The story of youth people returning from Syria, https://www.evropaelire.org/a/28074113.html 